\title{
APUNTES PARA UN DISCURSO DE CALIDAD EN LA COMUNICACIÓN DE RESULTADOS CIENTÍFICOS
}

\author{
Manuel Paulino Linares-Herrera1: Instituto de Información Científica y Tecnológica. \\ Cuba \\ mplinares106@gmail.com
}

Javier Ramón Santovenia-Díaz: Instituto Politécnico Fernando Aguado y Rico. Cuba interactivo@infomed.sld.cu

\section{RESUMEN}

Más allá del dominio de las reglas ortográficas y de poseer una adecuada redacción, es necesario por parte de los investigadores un estilo propio que se evidencie en el proceso de confección de los resultados. Hoy día toda comunicación de resultados científicos debe estar sustentada en los tratamientos que requieren los textos desde sus diversas disciplinas, el uso estratégico de la lingüística, la estilística y demás recursos de la semántica. Se evidencia lo importante que es trazar estrategias comunicativas para logar la necesaria eficiencia; constituyendo los apuntes, fundamentos y propuestas, elementos básicos para lograr un discurso comunicable, que responda a los intereses de las comunidades científicas y académicas.

PALABRAS CLAVE: Propósito Comunicable - Resultados de Investigaciones Calidad En La Comunicación Científica - Investigadores

\footnotetext{
${ }^{1}$ Autor correspondiente

Manuel Paulino Linares-Herrera1: Ingeniero y Máster en Ciencias de la Comunicación. Editor Jefe de la revista Ciencias de la Información del Instituto de Información Científica y Tecnológica. La Habana. Cuba. Correo:mplinares106@gmail.com
} 


\title{
NOTES FOR A SPEECH QUALITY IN COMMUNICATION OFSCIENTIFIC RESULTS
}

\begin{abstract}
Beyond the domain of spelling rules and an adequate wording is needed from researchers with a unique style that was evident in the manufacturing process of the results. Today, all communication of scientific results should be supported in treatments that require the texts from various disciplines, the strategic use of linguistic, stylistic and other resources of semantics. It is evident how important it is to devise communication strategies for attaining the necessary efficiency, constituting the notes, fundamentals and basic elements proposed to achieve a communicative discourse that responds to the interests of scientific and academic communities.
\end{abstract}

KEY WORDS: Communicative Purposes - Research Results - Quality Of Scientific Communication - Researchers

\section{INTRODUCCIÓN}

Es muy importante que se tenga la oportunidad de conocer y comprender los resultados del trabajo de investigación científica. No es suficiente que el conocimiento adquirido sea registrado, desarrollado y aplicado solo por algunos especialistas. La limitación del capital de conocimientos a su propio círculo es la muerte del espíritu filosófico de todo un pueblo y conduce al empobrecimiento intelectual. (Einstein, 1948)

La optimización del proceso de comunicación por parte de los investigadores, y sus dominios científico-técnico en los procedimientos de elaboración de los informes de investigación, resulta determinante en la actualidad para el desarrollo social y el cumplimiento de estrategias de desarrollo.

La interdisciplinariedad que caracteriza a sus contenidos, las propias tecnologías de la información y la comunicación presuponen trazar entonces estrategias comunicativas para lograr el éxito del propósito comunicable, propósito es el planteamiento de la investigación, y comunicable, es cuando cumple con los parámetros de un documento legible y entendible, según las instrucciones del Medio escogido para su comunicación.

Uno de los entornos de necesario dominio, es propiciado por la convergencia tecnológica, fundamentada en el uso de las herramientas y recursos de las tecnologías de la información y la comunicación; a través de las tecnologías se conforman y estructuran los contenidos haciendo ineludible la presencia de imágenes, 
comunicativa. Considerando que en las investigaciones en ciencias sociales, para la comunicación de los resultados son necesarias también las aplicaciones tecnológica de formas convergente.

En el proceso de comunicación científica los mensajes, discursos o textos, independientemente de su forma, claro, utilizan símbolos y códigos que responden a las características de las investigaciones y al estilo de trabajo de los autores; tras esta puntualización hay un arduo proceso estratégico en respuesta a la comunicación de resultados.

En el actual contexto mantienen vigencia importantes argumentaciones que definen a la comunicación desde diferentes criterios: Berelson y Steiner (Berelson \& Steiner, 1964) plantean precisar a la comunicación desde su transmisión, como propiedad fundamental, y la definen como la interrelación de información, ideas, emociones y habilidades (Berelson, 1964); por su parte, el autor Hernández Rivero (Hernández Rivero, 2001) conceptualiza su definición de comunicación apoyándose en la diversidad de medios de comunicación con que se cuenta, definiéndolo como el proceso de transmisión y recepción de ideas, información y mensajes.

El investigador al comunicar los resultados científicos, debe actuar con un conocimiento estructurado y organizado a través de la interacción y las percepciones evidenciadas en las múltiples situaciones que se presentan en su investigación. En la preparación y el dominio de las estructuras que tipifican a la tipología de los documentos científicos; y particularmente en el artículo y sus variantes; o sea el artículo de revisión bibliográfica, de investigación, y el artículo de comunicación de proyectos o estados de la investigación, los cuales se conciben trazando estrategias con mensajes diseñados sobre los principios e hipótesis del objetivo principal a comunicar, básico para lograr motivaciones y actuaciones. El objetivo principal debe estar presente, de una forma expresiva o $u$ otra, en todo el mensaje, es la esencia del éxito de la comunicación.

Como vía de comunicación se pueden utilizar diferentes formas expresivas, viables para la elaboración del discurso, según la etapa o estado en que se encuentra la investigación, que se pretende comunicar, y en respuesta a la premura que requiere su divulgación científica; es importante haber realizado una estratégica selección del Medio o revista para publicar los resultados de la investigación. Las formas o modalidades propuestas son el aviso, nota o crónica informativa para dar a conocer el proyecto investigativo, de forma inmediata y precisa, muy utilizado en repositorios académicos y científicos, además de sitios divulgativos y especializados en contenidos científicos.

Otra variante expositiva es poner a conocimiento el estado del proyecto, a través de manifestaciones descriptivas propias de la reflexión y el debate, como son los pósters, ponencias y conferencias, modalidades propicias para presentar en eventos 
documentos al recogerse en las memorias del evento, como constancia de sus debates. Todo lo planteado anteriormente contribuye a validar ante la comunidad científica los estados o fases de la investigación y sus resultados científicos y académicos.

\section{DESARROLLO}

\subsection{Innovación en sus contenidos}

La innovación en los contenidos permite elaborar con calidad el discurso a comunicar, aspecto indispensable para lograr el éxito ante la comunidad científica. El intercambio profesional puede proporcionar resultados alentadores, el trabajo colectivo, según el conocimiento de los involucrados en la investigación garantiza calidad.

La propuesta obtenida a partir de las consideraciones debatidas por profesores de la Facultad de Comunicación de la Universidad de La Habana, y estudiantes del diplomado Comunicar Ciencia, responden a una interrelación disciplinaria a partir de la adecuación de los paradigmas del marketing estratégico, conocidas como "las 7 C" (Rivero \& Piedra, 2008):

a) Credibilidad- Se consigue con una adecuada estrategia de búsqueda y clasificación documental y de fuentes.

b) Contexto - Ubicar el objetivo o planteamiento de la investigación, sobre las realidades de los entorno investigado. Desde miradas globales y sostenibles.

c) Contenidos - Concebirlo en base a la relación interés del emisor (autor), interés del público (receptor). Debe ser un tema tratado desde todos los enfoques de la actualidad posible.

d) Claridad - La sencillez en su redacción, importante, sustentados en el tecnicismo propio de las especialidades científicas y en los recursos lingüísticos que ofrece el idioma español.

e) Continuidad y consistencia - Incentivar desde la percepción del autor, al tratamiento del texto y su imagen, y llegar a la persuasión que se pretende con la comunicación de los resultados.

f) Canal de comunicación - Seleccionar la publicación ideal, según la temática, interés, niveles de impacto y estrategias a responder.

g) Capacidad pública - Lograr legibilidad y efectividad en el manejo del lenguaje que se comunica al usuario o lector, crédito del éxito en la comunicación de los resultados científicos.

Elemento señalado que apoyan el éxito esperado por los investigadores, es la calidad de la imagen comunicativa, la cual requiere de un trabajo preciso desde el inicio del proceso discursivo de la información a comunicar. Durante la estructura de los 
expresivos que justifique y admita el medio escogido para su publicación. Se trabaja de forma persuasiva, por la calidad comunicativa y por cumplimentar el propósito comunicable ante el público objetivo.

La autora Irina Kostina (Kostina, 2002), precisa en sus investigaciones sobre las tendencias que convocan a profundizar en el discurso de calidad durante el proceso de comunicación científica, enfatizando en diversas líneas de investigación tanto a nivel teórico como metodológico y de aplicación.

Propone proceder a estudiar la variación de los términos y conceptos en dimensiones múltiples; la teoría de la variación que permite articular en diferentes dominios de conocimiento y en textos de diferentes niveles de especialización a partir de formas textuales representativas, y hacer estudios comparativos de la variación conceptual en diferentes dominios, en textos de diferentes niveles de especialización y en diferentes lenguas, propone la autora (Kostina, 2002).

\subsection{Sobre propuestas comunicativas}

La comunicación de un artículo de revisión bibliográfica, propicia informar sobre la observación documental y sus fases de estudio, evidencia la existencia de un problema real sustentando en una estrategia de fuentes bien fundamentada, con un alto nivel de actualización.

Se concibe el artículo de investigación para comunicar estados de tendencias y resultados preliminares, todo de forma analítica, siguiendo el esquema de trabajo que recomienda el medio escogido; y el artículo de comunicación de proyectos o estados de la investigación sugiere una visión puntual del contenido investigativo que deriva fundamentalmente en el planteamiento del problema y la metodología a desarrollar.

Otros tipos de documentos que favorecen un discurso mucho más descriptivo y explicativo son las monografía que se contiene entre unas 40 y 70 páginas, ideal para incorporar de forma detallada, tablas, esquemas, resultados de encuestas, estadísticas y otros documentos que explicitan la investigación, el tratamiento monotemático a su contenido hace que se proyecte este desde todos los entornos involucrados en la investigación monotemática.

El proyecto de un libro especializado o ensayo científico, se crea de acuerdo a la estructura que orienta los procedimientos institucionales, se rige en la mayoría de los casos, por normas preestablecidas e internacionales y el tratamiento a sus contenidos responden a los niveles de especialización de la materia que se trate, y el contexto en que se propicia la investigación, desde sus antecedentes, elementos conceptualizaciones de apoyo hasta los resultados puntuales y detallados de la investigación, entre otros factores determinantes. 
A partir de las apreciaciones realizadas a los diferentes tipos de discursos en la comunicación científica, podemos resumir que las contribuciones en todas sus formas expresivas deben proponer un discurso de éxito. Otro aspecto determinante para la calidad de los contenidos es la correcta selección del medio, como habíamos puntualizado; actualmente matizada por la creciente repercusión e impacto de las tecnologías de la información y la comunicación, como son los repositorios o bases de datos en los que se archivan documentos inéditos o publicados, que han sido elaborados por los profesionales pertenecientes a las instituciones de investigaciones científicas, universidades, entre otras organizaciones.

Aún persisten dificultades ante el incremento de la visibilidad de las ideas y proyectos "aparentemente novedosos" y expuestos a través de sitios que propicia Internet y que no se encuentran aún validados, además sin una política definida de filtraje o selección de contenidos.

Estas ideas y proyectos, no encuentran apoyo en la comunidad científica, ni reconocimientos por parte de publicaciones especializadas reconocidas internacionalmente; principalmente el error radica en no someter a procesos de evaluación o arbitraje a estos tipos de documentos, motivando situaciones como:

a) Hipótesis no demostradas o validadas científicamente.

b) Imprecisiones en los planteamientos.

c) Alto nivel de incertidumbre en los datos.

d) Resultados preliminares a partir de revisiones bibliográficas de documentos de dudosa procedencia, entre otras malas prácticas.

Importante y determinante en toda investigación es el método o metodología a aplicar, debe ser tratada según los parámetros que la rigen, sustentados según las especialidades científicas. Los procedimientos cuánticos o cualitativos deben cumplir todos los requisitos normados y estipulados según el tipo de investigación y su diseño.

\subsection{Reflexiones en cuanto al tratamiento del discurso}

Como parte del tratamiento al discurso, deben los evaluadores o árbitros de contenidos científicos actuar como filtros mediante el análisis al discurso presentado como propuesta; la revisión a doble ciega, la cual orienta en su planilla de evaluación o arbitraje de documentos científicos, según lo describe cada publicación; otra de sus actuaciones debe estar dirigida a la eliminación de las barreras potenciales (sicológicas, ambientales y fisiológicas) que se producirían en el proceso comunicativo y que puedan afectar el objetivo de comunicación, debido entre otras causas a la errónea aplicación de los códigos de comunicación y los elementos lingüísticos.

Otra incidencia en el tratamiento del discurso, se manifiesta en las particularidades 
idioma; por ésta razón las distorsiones en los contenidos tiene su incidencia en las relaciones interculturales, elemento principal para el desarrollo de los contexto en los discurso o mensajes; según la obra investigativa de Mattelart (Mattelart, 1996); éste convoca desde sus reflexiones interculturales y humanísticas a debatir y actuar en función de los tiempos actuales, como necesaria respuesta, que retan y exigen los grandes contextos contemporáneos, son estos los que se convocan desde:

a) La tecnología y sus respuestas globales

b) La empresa como nuevo centro de gestión de las relaciones sociales

c) El intelectual como figura funcionada hacia los medios y el poder, y un nuevo orden mundial necesario ante el maniqueísmo norte/sur. (Mattelart, 1996)

Estos elementos se mantienen vigentes, particularizándose de acuerdo a los nuevos contextos que se desarrollan en el siglo XXI, como son:

a) Nuevos soportes comunicativos: redes sociales, redes científicas y académicas, entre otros.

b) Nuevas políticas en el acceso a la información, como lo es el Acceso Abierto.

c) Normativas, legislaciones y pautas que integra a la investigación científica mundial y proyecta en pos del desarrollo sostenible.

d) Desarrollo de repositorios especializados en función de la comunidad científica internacional, que propician publicar resultados científicos y divulgarlos para socializarlos en beneficio del desarrollo.

\subsection{Proceso del discurso a comunicar}

El cumplimiento de los procesos de comunicación: organización, clasificación, y tratamiento a las formas expresivas, garantizan la interacción comunicativa en pos de un objetivo aplicable, entiéndase este, como resultado del objetivo o planteamiento a investigar para beneficio de toda la comunidad científica. Se asume además el aporte que la lingüística, la literatura, la retórica y la estilística tributan desde sus normas y métodos a la descripción de la estructura de los textos del propósito comunicable. También ocupa un importante papel el tratamiento a los procesos cognitivos y afectivos, las actitudes y estructuras de los entornos sociales y económicos, los modos de producción y otros muchos aspectos que responden a especialidades científicas, propias de las ciencias sociales, naturales, médicas $u$ otras ciencias y disciplinas científica.

Como método de investigación para procesar la propuesta comunicativa, se propone tener presente al análisis de contenido, dentro del marco de la investigación cualitativa. Su aplicación tributa a la profundización desde el punto de vista 
cual propicia un tratamiento en aras de optimizar la calidad de la comunicación científica. En respuesta a esta reflexión, y argumentándose desde la diversidad idiomática, disciplinaria y cultural; apunta Dijk Van (Dijk Van, 1992), "se presenta como una tendencia el uso de la lengua, la comunicación y sus formas convergentes de expresión, de manera interdisciplinaria", plantea el autor. Esta interrelación o interindisciplinariedad es válida para las diferentes ramas científicas y motiva tendencias homogenizadoras en la comunicación de los resultados, nuevas líneas en el tratamiento de los contenidos científicos se perfilan.

Una de las herramientas que proporciona definiciones semánticas e ideográficas, son los diccionarios especializados en terminologías; éstas representaciones de ideas y palabras a través de imágenes o símbolos permiten una diversa orientación ante los diferentes públicos que acceden a los contenidos científicos; según lo planteado en las diferentes disciplinas propias de las ciencias sociales. (Fernández González de Chávez, 2009)

Está representación de ideas y palabras cumplen un propósito comunicable, una función socializadora, ya sea a través de un discurso textual, audiovisual o de imagen; que sea capaz de crear en sus lectores capacidad para entender, extraer información, analizarla, clasificarla, procesarla, aplicarla y enriquecerla.

La hipótesis por la cual sustentamos lo antes expuesto se fundamenta en el tratamiento especializado que requieren los contenidos a comunicar. Como parte del procedimiento que el autor (Cabrera Suárez 2008), vincula a la forma y contenido con el lenguaje y su comunicación de forma inseparable, reafirmando el autor, "ante las diversas connotaciones de las voces sinónimas, debe tenerse un especial cuidado ante los idénticos significados de muchas palabras".

Otro criterio se expone desde la concepción de la composición de los contenidos; su línea explicativa en la redacción de documentos, es la composición progresiva consecutiva la cual encamina, al análisis y la obtención de propiedades a que conduzcan necesariamente a la generalización desde sus formas expositivas y sus conexiones casuales. Precisa el anterior planteamiento y traza Ortega Rodríguez (Ortega Rodríguez, 2009), "es lo idóneo para expresar por escrito el pensar orientado hacia el conocimiento de las dependencias internas de los objetos y fenómenos".

Autores como Piezzi (Piezzi, 2010), apunta que se requiere de verdaderos desafíos para captar el interés de buenos contenidos científicos, por lo que sugieren tener en cuenta a la hora de redactar y conformar al discurso: la calidad de impresión(tipos de fuentes tipográficas, formatos de imágenes y textos y otros) y de diseños gráficos acordes a los procesos tecnológicos de punta que aplica la publicación seleccionada (plataformas de gestión editorial que utilizan, infografías, audiovisuales, especialidades sonoras, entre otras, ejemplo la plataforma de gestión editorial, Open Journal Systems). 
internacionalización, sus comités de redacción, consultores y especialistas; decisiones sobre la adopción de los patrones de difusión, producción y circulación, acordes éstos con gestiones y pautas reconocidas por la comunidad científica y académica internacional, entre otros patrones que perciben el éxito. (Piezzi, 2010)

\subsection{Aspectos a precisar en la redacción científica}

No resulta ocioso reiterar que la exposición del mensaje con precisión, claridad y coherencia, es determinante para evitar la presencia de barreras psicológicas, idiomáticas y cognitivas que distorsionan los mensajes y le restan calidad e impacto.

Según el tratamiento a los principios de la redacción gramatical y a los recursos de la comunicación serán más o menos visibles e impactantes las barreras en el discurso científico. Otras problemáticas, como la ambigüedad, la reiteración e incoherencia, la aplicación incorrecta de la metodología de investigación y del estilo bibliográfico, son dificultades determinantes y a solucionar para ser del discurso o mensaje un propósito comunicable.

No deben olvidarse que la normativa indispensable para una comunicación de calidad, es la de concebir desde su inicio una redacción comprensible y objetiva, entre otras muchas particularidades del estilo y la semántica. Teniendo a la redacción científica como proceso clave para ordenar las ideas a comunicar se debe perfeccionar la coherencia al escribir; planificando el tiempo para la revisión y aplicando principios de la redacción científica, tales como: precisión, claridad y brevedad. (Ver Tabla 1). 
Tabla 1. Tres de los principios de la redacción científica

\begin{tabular}{|c|c|c|}
\hline \multirow[t]{2}{*}{ Principios } & \multicolumn{2}{|c|}{ Ejemplos } \\
\hline & Incorrecto & Correcto \\
\hline $\begin{array}{l}\text { Precisión: usar las } \\
\text { palabras que } \\
\text { comunican } \\
\text { exactamente. }\end{array}$ & $\begin{array}{l}\text { El plegable promocional que } \\
\text { contiene la convocatoria se } \\
\text { distribuyó mejor en las salas } \\
\text { B y C, resultando un buen } \\
\text { impacto. }\end{array}$ & $\begin{array}{l}\text { El plegable promocional de la } \\
\text { convocatoria, impactó, se } \\
\text { distribuyó en las salas B y C. }\end{array}$ \\
\hline $\begin{array}{l}\text { Claridad: } \\
\text { atribuye a } \\
\text { comprensión y } \\
\text { objetividad del } \\
\text { texto. }\end{array}$ & \multicolumn{2}{|c|}{\begin{tabular}{l|l} 
Ante los ataques del hombre & Ante el descuido del hombre \\
a la naturaleza, se & por la naturaleza, el cambio \\
desarrollan las posibilidades climático se acelera, siendo \\
de peligro, el cambio & evidente en todas las regiones \\
climático se hace más & del planeta. \\
evidente, por lo que se & \\
despliega por todo el & \\
planeta. &
\end{tabular}} \\
\hline $\begin{array}{l}\text { Brevedad- } \\
\text { comunicar la idea en } \\
\text { pocas palabras }\end{array}$ & $\begin{array}{l}\text { Fueron } 7 \text { los días de } \\
\text { trabajo para lograr los } 56 \\
\text { casos que resultaron de la } \\
\text { investigación, los cuales } \\
\text { fueron distribuidos a } \\
8 \text { por } \\
\text { día. }\end{array}$ & $\begin{array}{l}\text { Durante la investigación se } \\
\text { obtuvieron } 56 \text { casos, en } 7 \\
\text { días de trabajo. }\end{array}$ \\
\hline
\end{tabular}

Son los expuestos, principios determinantes que se van conjugando a medida que se redacta el discurso de los resultados científicos, de acuerdo a su estructuración y estrategias. Lo caracteriza el tratamiento a las diferentes disciplinas científicas que desde sus glosarios técnicos y el uso de términos y palabras comunes, precisan y justifican los sucesos conformando un texto final.

\section{CONCLUSIONES}

Las revistas y publicaciones científicas en general se encuentran ante un reto difícil y ampliamente discutible desde aspectos éticos, valorativos y cognitivos en general consistente en que los investigadores poseen vías alternativas para socializar libremente los resultados de sus investigaciones como son los repositorios institucionales, los Weblogs, las listas de distribución, las comunidades virtuales, entre otros, modalidades diversos, que conlleva a un mejor estudio y selección del Medio en el cual comunicar los resultados científicos, clave para el reconocimiento y la validación de la investigación científica a proponer. 
investigación, sus objetivos e hipótesis, el estableciendo de comparaciones entre los resultados obtenidos, con otros trabajos de investigación relacionados con el marco de referencia $u$ objetivos propuestos, son de los elementos que se puntualizan y determina calidad en los contenidos.

Se patentiza con estos apuntes, que el desafío mayor del investigador es comunicar sus resultados desde una estrategia viable en cumplimiento de los requisitos de las publicaciones seleccionadas y en base a los objetivos trazados para el éxito de su comunicación.

Las consideraciones que sobre el campo de la comunicación de los resultados científicos se plantean constituyen fundamentaciones válidas, y propuestas para lograr un discurso de éxito.

No pretendemos que constituya una guía lo aquí apuntado, pero si apreciadas consideraciones, para que la propuesta del discurso de calidad, contribuya a implementar con objetividad sus ofertas de aplicación, además propiciar nuevos proyectos sostenibles para el desarrollo y en bien de la Humanidad.

\section{REFERENCIAS}

Berelson, B \& Steiner, G H. (1964). Human behavior: an inventory of scientific findings. Nueva York: Harcourt, Brace and World, Inc..

Cabrera Suárez, N. (2008). Lenguaje y Comunicación. La Habana: Editorial Félix Varela.

Dijk Van, J. A.(1992). La ciencia del Texto. Barcelona: Ediciones Paidós Iberica.

Fernández González De Chávez, M. (2009). Diccionario Semántico Ideográfico, de la noción del saber. La Habana: Editorial Félix Varela.

Hernández Rivero, M \& Pons Torrente, I. (2001). Comunicación empresarial. La Habana: Instituto de Comercio Exterior.

Kostina, I. (2002). La variación conceptual de los términos en el discurso Especializado. Bienni: Institut Universitari de Lingüística Aplicada Univeritat Pompeu Fabra.

Mattelart, A. (1996). La comunicación-mundo. Historias de las ideas y de las estrategias. México: Editorial Siglo XXI.

Ortega Rodríguez, E. (2009). Redacción y Composición II. La Habana: Editorial Felix Varela. 
las ediciones científicas de la región. Revista BIOCELL.

Rivero, M. \& Piedra, M. (2008). Tendencias de la comunicación. La Habana: Universidad de La Habana.

\section{Manuel Paulino Linares-Herrera}

Ingeniero Geodesia y Cartografía y Máster en Ciencias de la Comunicación, Periodismo. Vinculado desde sus comienzos laborales a las actividades editoriales. Ha participado en diversos proyectos sobre comunicación científico-técnica y edición especializada. Ha publicado en revistas y periódicos especializados desde diferentes formas discursivas: notas de prensa, artículos, reportaje, análisis, artículo científico y otros. Ha impartido cursos, talleres y conferencias, sobre sus temáticas afines. Ha participado en eventos nacionales e internacionales como ponente y observador. Es miembro de la Sociedad Cubana de Ciencias de la Información (SOCICT) y de la Asociación de Comunicadores Sociales (ACCS).

\section{Javier Ramón Santovenia-Díaz}

Licenciado en Información Científica-Técnica y Bibliotecología en la Facultad de Artes y Letras de la Universidad de La Habana. Máster en Ciencias de la Educación. Es responsable de la Biblioteca y del Dpto. de la asignatura de Organización de bibliotecas del Instituto Politécnico Fernando Aguado y Rico. Es Miembro del Ejecutivo Nacional de la Sociedad Cubana de Ciencias de la Información. Pertenece al Grupo Profesional de Gestión de Conocimiento de la Asociación Cubana de Bibliotecarios (ASCUBI). Es editor asociado de la Revista Acimed y de la Revista Ciencias de la Información. 